\title{
La protección judicial del derecho a la memoria: la remoción de las imágenes de un genocida
}

\author{
Comentario de Pietro Sferrazza Taibi* y \\ Francisco Bustos Bustos**
}

Santiago, veintiséis de diciembre de dos mil diecinueve.

Vistos:

Comparece don Luis Mariano Rendón Escobar, abogado, RUT 8.938.681-0, interponiendo acción constitucional de protección, por sí, en su calidad de integrante de la "Nómina de Prisioneros Políticos y Torturados", elaborado por la "Comisión Valech II" y a nombre de las otras personas sobrevivientes que figuran en esa nómina "y en las otras que enlistan a las víctimas de violaciones a los derechos humanos”, por la omisión ilegal y arbitraria que atribuye al Ejército de Chile, que resultaría vulneradora de su derecho a la integridad psíquica.

Explica que la omisión de la que reclama atañe a la negativa del Ejército de Chile de retirar placas e imágenes conmemorativas del paso de Manuel Contreras Sepúlveda por dicha institución, las que se encuentran ubicadas en la Academia de Guerra y en la Escuela de Ingenieros de Tejas Verdes. Acentúa el recurrente que el Ejército de Chile, como todo órgano del Estado, se encuentra obligado a respetar y promover los derechos esenciales que emanan de la naturaleza humana y que, en lugar de ello, "conmemora el paso por sus recintos del principal violador de tales derechos en la historia de Chile".

Se aduce en el recurso que la omisión reclamada constituye una perturbación permanente al derecho a la integridad psíquica que consagra a favor suyo el artículo 19 $\mathrm{N}^{\circ} 1$ de la Carta Fundamental. Acerca de cómo se provoca esa vulneración, se indica que la permanencia de esas placas e imágenes comporta una violación al principio "garantía de no repetición".

* Licenciado en Ciencias Jurídicas y Sociales, Universidad de Valparaíso, Chile. Doctor en Estudios Avanzados en Derechos Humanos, Universidad Carlos III de Madrid, España. Profesor de la Facultad de Derecho, Universidad Andrés Bello. ORCID: https:/orcid.org/0000-0003-1133-9221. Correo electrónico: pietrosferrazza@gmail.com.

** Licenciado en Ciencias Jurídicas y Sociales, Universidad de Chile. Magíster en Derecho, mención Derecho Internacional, Universidad de Chile. Magíster en Derecho Internacional de los Derechos Humanos, Universidad Diego Portales, Chile. Profesor de la Facultad de Derecho, Universidad Andrés Bello, Chile. ORCID: https://orcid.org/0000-0003-1013-7206. Correo electrónico: fbustos@derecho.uchile.cl 
Recuerda que a través de la Resolución 60/147, de la Asamblea General de las Naciones Unidas, adoptada en la 64ª Sesión Plenaria, se declaró el derecho a una "Reparación adecuada" de las víctimas en casos de violaciones de los Derechos Humanos. Allí se consagró la "garantía de no repetición” como una de esas formas de reparación. En concreto, en el N 23 de dicha Resolución se indica que las garantías de no repetición comprenden, entre otras medidas, las que siguen: "a) El ejercicio de un control efectivo por las autoridades civiles sobre las fuerzas armadas y de seguridad...”; “...e) La educación, de modo prioritario y permanente de todos los sectores de la sociedad respecto de los derechos humanos y del derecho internacional humanitario y la capacitación en esta materia de los funcionarios encargados de hacer cumplir la ley, así como de las fuerzas armadas y de seguridad...".

Pues bien, dice el recurrente, las imágenes y placas aludidas cumplen un rol nefasto, porque mostrarían a Manuel Contreras, ante las nuevas generaciones de oficiales tropa del Ejército, "como un oficial normal y decente", normalizándose de ese modo su comportamiento criminal y, en sus palabras, a tal conducta se "la muestra implícitamente como parte del deber militar que podría ser necesario volver a cumplir”. Subraya también lo inconveniente de que esas imágenes y placas se mantengan en espacios educativos.

Solicita que esta Corte disponga el retiro respectivo y que en su reemplazo se incorpore un extracto de la sentencia que falle este recurso, como forma concreta de reparación.

Se apersona el General de Ejército, Comandante en Jefe del Ejército de Chile, don Ricardo Martínez Menanteau, evacuando el informe ordenado a su respecto, solicitando el rechazo de la acción constitucional de que se trata, en virtud de las razones y planteamientos que siguen:

1.- Falta de legitimación pasiva: El Ejército de Chile forma parte de la Administración centralizada del Estado, carece de personalidad jurídica propia, de manera que el señor Comandante en Jefe no tiene su representación judicial. La acción debió ser dirigida contra el Consejo de Defensa del Estado;

2.- Improcedencia de la acción de protección: El recurso intentado no es el medio idóneo para exigir el retiro de las placas y fotografías. En efecto, tanto la Academia de Guerra como la Escuela de Ingenieros del Ejército son predios fiscales que, además, constituyen recintos militares. Lo que se pretende es que a través de esta vía cautelar se intervenga al interior de un recinto militar, lo que está lejos de la naturaleza de esta acción. Además, la supuesta afectación de la integridad psíquica del recurrente requeriría de algún tipo de prueba pericial, en circunstancias que esta clase de procedimiento no contempla un período de discusión y prueba;

3.- Inexistencia de la omisión ilegal y arbitraria: En primer término, se hace notar

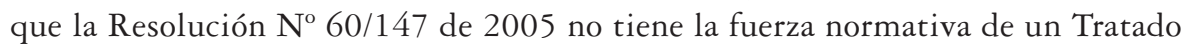
Internacional, no crea nuevas obligaciones, sólo propone mecanismos o pautas de conducta que permitan hacer efectiva la reparación del da o en materia de derechos humanos. En cualquier caso, no se vislumbra cómo se vulneraría la "garantía de no repetición” por el no retiro de las fotografías y efectos del General de Brigada (R) Contreras, "las cuales sólo se encuentran por razones de registro histórico 
militar, pues no constituyen de ninguna manera y bajo ningún precepto homenaje, conmemoración u otra forma de resaltar la figura de dicho oficial”. Tampoco se vulnera la debida educación que se imparte a miembros del Ejército en materia de Derechos Humanos. En tal sentido, se destacan los contenidos de orden humanitario que se imparten actualmente en las escuelas matrices de las fuerzas armadas, insertos en el Primer Plan Nacional de Derechos Humanos 2018-2021, regido por la Ley 20.885, que crea la Subsecretaría de Derechos Humanos;

4.- Inexistencia de la vulneración de la integridad psíquica del recurrente: No se produce tal afectación porque la consecuencia de no retirar las fotografías y placas "no es más que el ejercicio de un hecho que se realiza en un bien fiscal de carácter militar, en el cual el ingreso y salida del mismo es restringido y respecto del cual la institución tiene el deber de administrar, lo que genera que la cuestionada omisión..., constituya un hecho plenamente legítimo" (Sic). Añade que no se observa que la omisión acusada cause una amenaza real e inminente, grave y manifiesta a la integridad psíquica del Sr. Rendón, que por lo demás no está comprobada y se limita a una manifestación de temor que futuros integrantes de la institución repitan conductas del GDB (R) Contreras;

5.- Inexistencia de un derecho indubitado: Para que proceda la medida de protección impetrada debe ser indiscutido que la integridad psíquica ha sido amenazada. Sin embargo, el recurrente no aporta indicios ni menos pruebas de la lesión a ese derecho fundamental, menos aun si ni siquiera conoce las fotografías o placas cuyo retiro reclama.

Se ordenó traer los autos en relación y se dispuso la agregación extraordinaria de esta causa en la Quinta Sala.

\section{Considerando:}

\section{I.- Sobre una cuestión previa}

Primero: Conforme se expuso, el Ejército de Chile postula como primera cuestión a dilucidar lo que denomina su "falta de legitimación pasiva". De acuerdo con la Carta Fundamental la acción constitucional de protección puede ejercerla el propio afectado "o por cualquiera su nombre", mientras que el Auto Acordado respectivo autoriza para interponerla "por escrito en papel simple o por cualquier medio electrónico". Lo que se busca poner en relieve es que esta acción no está sujeta a rigores formales, cualidad que resulta coherente con el imperativo de rapidez, eficacia y sencillez que debe caracterizarle, de manera que le resultan ajenas e impropias alegaciones como las planteadas por la recurrida, en orden a que la acción debió enderezarse contra el Consejo de Defensa del Estado. Comoquiera que sea, un arbitrio de esta índole debe substanciarse con la persona, funcionario o entidad que cause el acto que se tacha de ilegal o arbitrario. En este caso la imputación atañe a una omisión atribuible al Ejército de Chile, órgano que comparece informó acerca del fondo del asunto; 
II.- Sobre el recurso, su idoneidad y la omisión reprochada

SEGUNDO: El recurso de protección es una acción cautelar de ciertos derechos fundamentales que busca poner freno a los menoscabos que puedan experimentar tales derechos como consecuencia de acciones u omisiones -ilegales o arbitrarias-, atribuibles a la autoridad o particulares.

Así, constituyen presupuestos de esta acción cautelar, los siguientes: a) que exista una acción u omisión ilegal o arbitraria; b) que producto de esa acción u omisión ilegal o arbitraria se prive, perturbe o amenace un derecho; y c) que tal derecho esté señalado como objeto de tutela en el artículo 20 de la Constitución Política de la República;

Tercero: Cuando están comprometidos los derechos fundamentales, no puede haber cotos vedados o espacios que estén al margen de la adopción de medidas de restablecimiento en un mecanismo de tutela judicial de urgencia como éste. Nada hay en el texto ni el sentido final del artículo 20 de la Carta Fundamental que sea al menos indiciario de que -en palabras de la recurrida-, no pueda "intervenirse" por este medio en un recinto militar;

\section{III.- Sobre la omisión y su carácter arbitrario}

CuARto: En la especie la que se tacha de ilegal y arbitraria es la negativa manifestada por el Ejército de Chile de retirar unas placas y fotografías del General de Brigada (R) del Ejército de Chile, Manuel Contreras Sepúlveda;

Quinto: Ya se dijo que una de las condiciones de procedencia del arbitrio de protección está constituida por la cualidad de arbitraria de la inacción o de la negativa a actuar por parte de la autoridad en un sentido determinado. Acostumbra a señalarse que lo arbitrario es sinónimo del mero "capricho". Tal acepción -aunque correcta-, tiende a resultar muy restringida cuando se trata de examinar la eventual vulneración de derechos fundamentales por parte de órganos o autoridades públicas. En una comprensión más amplia, la arbitrariedad puede asumirse como la falta de sustento para los actos de decisión, para el ejercicio del poder. En un estado de derecho todas las autoridades -incluidas las del orden jurisdiccional, por cierto- están llamadas no sólo a explicar sino que a justificar sus decisiones.

Esta exigencia implica la necesidad de motivaciones susceptibles de aceptar por un observador razonable, al punto que no pueda haber mejores razones que las desvirtúen. Esto que se dice cobra mayor relevancia en situaciones como la que es materia de esta causa, en que se hace preciso una suerte de ponderación de razones;

Sexto: El Ejército de Chile ha justificado su proceder aduciendo que las placas y fotografías de Contreras Sepúlveda, ubicadas en la Academia de Guerra y en la Escuela de Ingenieros de Tejas Verdes, "sólo se encuentran por razones de registro histórico militar, pues no constituyen de ninguna manera y bajo ningún precepto homenaje, 
conmemoración u otra forma de resaltar la figura de dicho oficial". Se añadió también que su mantenimiento "no es más que el ejercicio de un hecho que se realiza en un bien fiscal de carácter militar, en el cual el ingreso y salida del mismo es restringido y respecto del cual la institución tiene el deber de administrar, lo que genera que la cuestionada omisión..., constituya un hecho plenamente legítimo";

SÉptimo: Empero, es un hecho de público conocimiento que el General de Brigada Manuel Contreras Sepúlveda fue condenado en múltiples procesos penales como autor de graves atentados y violaciones a los derechos humanos, constitutivos de crímenes de lesa humanidad, contándose entre ellos los delitos de homicidio calificado y de secuestro o desaparición forzada de personas.

Octavo: El art culo 63.1 de la Convención Americana de Derechos Humanos consagra el deber de los Estados de reparar las consecuencias derivadas de la vulneración de los derechos fundamentales. Un intérprete especialmente autorizado ha expresado sobre el particular que "Este artículo constituye una norma consuetudinaria que es, además, uno de los principios fundamentales del derecho de gentes..." (Corte Interamericana de Derechos Humanos, Caso Aloebetoe y otros vs. Surinam, sentencia de 10 de septiembre de 1993, apartado o párrafo 43). Desde esa perspectiva, cualquiera que sea la fuerza vinculante de la Resolución 60/147, de la Asamblea General de las Naciones Unidas, puede entenderse que cuando allí se alude a la garantía de no repetición no se hace otra cosa que relevar un deber elemental: la necesidad acudir a instrumentos o implementar medidas que propendan a evitar la repetición de conductas que han comportado la vulneración sistemática y masiva de derechos humanos.

Ocurre que para ese fin el pago de compensaciones en dinero sencillamente no es la adecuada. Antes bien, las medidas que se orientan a una educación integral en la materia -que no la mera instrucción o simple entrega de contenidos-, o aquellas que propician la formación de una verdadera cultura en derechos humanos, se presentan como mecanismos más idóneos para la consecución de tales fines. Así se comprende, por ejemplo, que el "Plan Nacional de Derechos Humanos" incluya dentro de sus acciones la instalación de placas conmemorativas de violaciones de derechos humanos en recintos militares (disponible en www.planderechoshumanos.cl, acción "Dictadura y Memoria”, Meta $\mathrm{N}^{\mathrm{3}}$ );

Noveno: Entonces, el cuestionamiento que cabe hacerse es si el registro histórico/ estadístico del paso y funciones cumplidas por Manuel Contreras Sepúlveda por centros educativos y de formación del Ejército de Chile es razón suficiente que justifique mantener su fotografía y placas en dichos recintos. Y en eso se advierte una falta de adecuación o carencia de proporcionalidad. Si de registros históricos se trata, pues para ello bastan las anotaciones en libros, fichas o documentos de destinaciones o nombramientos. Por ende, conservar esa otra clase de testimonios -aparte de contraproducente con la existencia de un "Plan Nacional de Derechos Humanos"-, resulta del todo innecesario para ese fin, hasta llegar a desbordarlo. En efecto, en el caso de la Academia de 
Guerra, las fotografías se ubican en las galerías de promoción de oficiales, de profesores y directores, en tanto que las placas lo son por "Mérito al Honor" y como Director de esa academia; y, tratándose de la Escuela de Ingenieros de Tejas Verdes, las placas son alusivas al cuadro de mando de la Secretaría de Estudios, a la primera antigüedad del curso de tenientes y como Director del Instituto.

Al ser así, máxime en las circunstancias apuntadas, la omisión que se acusa deviene en arbitraria;

IV.- Sobre la afectación de la integridad psíquica

Décimo: El reconocimiento de la dignidad de las personas forma parte esencial de las bases de nuestra institucionalidad. Como manifestación inherente de tal dignidad, directamente imbricada con ella, el artículo $19 \mathrm{~N}^{\circ} 1$ de la Constitución Política de la República reconoce el derecho a la vida "y a la integridad física y psíquica de la persona”. Por su lado, el artículo 5 de la Convención Americana de Derechos Humanos consagra el derecho a la integridad personal, prescribiendo a ese efecto que "Toda persona tiene derecho a que se respete su integridad física, psíquica y moral”. Por consiguiente, en la dimensión que interesa, ciertos menoscabos a bienes de la personalidad, a sus atributos de orden inmaterial o espiritual, pueden ser constitutivos de una afectación a la integridad psíquica de la persona. Por cierto, no se trata de identificar una lesión susceptible de ser indemnizada, como acontece con el daño moral en materia de responsabilidad civil. Lejos de ello, ese atributo de la personalidad debe ser protegido ante la simple "perturbación o amenaza";

Undécimo: Se ha sostenido por el Ejército de Chile que no existiría comprobación alguna ni indicios de la lesión al derecho fundamental invocado por el recurrente y que menos podría haberla si quien recurre ni siquiera conoce las fotografías o placas que exige que sean retiradas. A ese respecto cabe expresar que el señor Rendón Escobar acreditó estar incluido en el listado de Prisioneros Políticos y Torturados elaborado por la "Comisión Valech II". Expresado en otros términos, corresponde a una víctima directa de violación a sus derechos fundamentales en el período dictatorial. Pues bien, al amparo de criterios de normalidad, de esa condición de víctima es posible inferir la perturbación que representa para su integridad psíquica el solo hecho de saber que uno de los principales responsables de tal clase de atentados sigue figurando presente con menciones a su nombre, cargos ocupados y honores logrados, en placas e imágenes, todas ubicadas en recintos militares, que inclusive están destinados a la formación de oficiales y especialidades;

Duodécimo: Al ser así, esto es, al existir una omisión de carácter arbitrario que compromete un derecho fundamental de quien ha ejercido la acción constitucional, esta Corte debe adoptar una medida que permita restablecer el imperio del derecho, bastando para ese fin disponer el retiro respectivo. En particular, no se advierte la necesidad de incorporar, además, un extracto de esta sentencia, porque su sociabilización puede 
integrarse a la labor educativa que la institución tiene que llevar a cabo, como parte de sus programas formativos.

Por estas razones y de conformidad con lo previsto en el Auto Acordado de la Excma. Corte Suprema pertinente a la materia, se acoge la acción constitucional de protección interpuesta a su favor por don Luis Mariano Rendón Escobar. Por consiguiente, se ordena al Ejército de Chile efectuar el retiro de las imágenes y placas correspondientes al GDB (R) Manuel Contreras Sepúlveda, que se encuentran ubicadas actualmente en la Academia de Guerra y en la Escuela de Ingenieros de Tejas Verdes.

Se fija un plazo de 3 días para cumplir lo ordenado, contados desde que este fallo quede firme, debiendo darse cuenta a esta Corte de su ejecución.

Redactó el ministro señor Astudillo.

Regístrese y oportunamente, archívese.

Rol No 79.631-2019.-

Pronunciado por la Quinta Sala de la C.A. de Santiago integrada por los Ministros (as) Omar Antonio Astudillo C., Jenny Book R. y Abogada Integrante Carolina Andrea Coppo D. Santiago, veintiséis de diciembre de dos mil diecinueve.

En Santiago, a veintiséis de diciembre de dos mil diecinueve, notifiqué en Secretaría por el Estado Diario la resolución precedente.

\section{COMEnTARio}

En este caso, la Quinta Sala de la Corte de Apelaciones de Santiago resolvió acoger, por unanimidad, la acción de protección deducida por un sobreviviente de prisión política y tortura, ordenando que el Ejército de Chile retire de la Academia de Guerra y la Escuela de Ingenieros de Tejas Verdes las imágenes y placas correspondientes a Juan Manuel Contreras Sepúlveda, al ser de público conocimiento que como Director de la DINA fue condenado en casi un centenar de procesos criminales por ejecuciones extrajudiciales, secuestros (desapariciones forzadas) y torturas, todos delitos constitutivos de crímenes de lesa humanidad.

El pronunciamiento de la Corte de Apelaciones, confirmado por la Corte Suprema ${ }^{1}$, resulta de especial interés por permitir abordar el derecho a la memoria y sus relaciones con el derecho a la reparación. Si bien han existido previamente otras controversias judiciales relativas a la memoria -como la sentencia de primera instancia por la desaparición forzada de Álvaro Vallejos Villagrán, revocada en lo civil; los recursos de protección deducidos por víctimas y sobrevivientes con ocasión de la condecoración otorgada por un municipio a la Escuela de Ingenieros Militares de Tejas Verdes en 2017, donde las autoridades se vieron obligadas revertir dicha decisión ${ }^{2}$; u otros casos más recientes como

${ }^{1}$ Corte Suprema, 05.03.2020, Rol 14.720-2020. Esta resolución declaró inadmisibles los recursos deducidos.

${ }^{2}$ Sferrazza y Bustos, 2019, pp. 49-50. 
la sentencia de primer grado en el proceso “Operación Cóndor”, pendiente de apelación, y el recurso de protección que rechazó el retiro de la Estatua de José Toribio Merino ubicada en el Museo $\mathrm{Naval}^{3}$-, al tratarse del primer fallo ejecutoriado, esta resolución constituye un hito a destacar.

El derecho a la memoria no está consagrado expresamente en un tratado internacional. Sin embargo, algunos instrumentos de soft law lo mencionan a propósito del derecho a la reparación. Por ejemplo, en relación con el sistema universal de derechos humanos el Conjunto de Principios actualizado para la Protección y la Promoción de los Derechos Humanos mediante la Lucha contra la Impunidad contiene una sección dedicada al derecho a saber ${ }^{4}$. Por su parte, en cuanto al sistema interamericano de derechos humanos, la Corte Interamericana de Derechos Humanos (Corte IDH) ha considerado que la realización de actos y obras de repercusión pública que contribuyen a la recuperación y conservación de la memoria constituyen una forma simbólica de reparación de daños inmateriales y ha agregado que la investigación y sanción de los responsables de violaciones de derechos fundamentales es una forma de reivindidación de la memoria de las víctimas que permite dar consuelo a sus deudos y resignificar la reprobación oficial de dichas violaciones 5 . Por tanto, la memoria ha comenzado a recibir paulatinamente una atención por parte del Derecho internacional de los derechos humanos, tanto en el sistema universal de protección como el interamericano. No es casualidad que la sentencia en comento invoca como fundamento de su decisión la obligación estatal de reparación consagrada en el art. 63 de la Convención Americana sobre Derechos Humanos (CADH) (consid. octavo).

Ahora bien, es interesante la argumentación de la sentencia acerca de la afectación del derecho a la integridad psíquica. El fallo asume que una víctima de graves violaciones a los derechos humanos experimenta una intensa aflicción espiritual por el solo hecho de saber que en dos establecimientos militares del Estado existen placas e imágenes ubicadas en lugares honoríficos, para conmemorar a unos de los más despiadados perpetradores de los crímenes del pasado reciente (consid. décimo), descartando además la exigencia revictimizadora propuesta por el recurrido, de acompañar peritajes psíquicos.

En conexión con este argumento, es admisible comentar que ante la falta de positivación del derecho a la memoria, es posible demandar su protección por la vía judicial mediante la invocación de derechos civiles o políticos tradicionalmente contenidos en el catálogo de derechos constitucionales. Asumiendo esta premisa, puede ser útil realizar un ejercicio interpretativo de los derechos del art. 19 de la Constitución chilena, con el fin de determinar qué derechos podrían mediar para perseguir este propósito ${ }^{6}$. Así

${ }^{3}$ Ministro Mario Carroza, 21.09.2018, Rol 2182-98 “Operación Cóndor”, Parte resolutiva III(q); CS, 19.02.2020, Rol 15.310-2020.

${ }^{4}$ Comisión de Derechos Humanos, 2005, párrs. 17-35.

${ }^{5}$ Cfr. Corte IDH, 03.12.2001, Serie C No 88, párr. 53; Corte IDH, 22.02.2002, Serie C No 91, párr. 56; Corte IDH, 27.02.2002, Serie C No 92, párr. 77; Corte IDH, 25.11.2003. Serie C No 101, párr. 278. Para la relación entre memoria, investigación y sanción, vid. Corte IDH, 18.09.2003, Serie C No 100, párr. 105. Acerca del tratamiento de la memoria en la jurisprudencia de la Corte IDH, vid. DulitzKy, 2017, pp. 581-604.

${ }^{6}$ Luther, 2010, pp. 52-55, realizando un ejercicio similar en relación con la Constitución española. 
como lo sostuvo la sentencia en comento, la memoria como función psicológica puede protegerse mediante el derecho a la integridad psíquica (art. $19 \mathrm{~N}^{\circ} 1$ ), ya que este derecho permite tutelar afectaciones graves derivadas de la apología o la negación de violaciones a los derechos humanos.

Por su parte, el derecho a la honra protege la proyección de la dignidad a nivel social y permite defender al titular frente a las ofensas proferidas en su contra o en perjuicio de sus familiares, incluyendo a sus difuntos (art. $19 \mathrm{~N}^{\circ} 4$ ). Asimismo, la memoria puede ejercerse en un espacio de intimidad que está tutelado por los derechos protectores de la privacidad (art. 19 n's 4 y 5). La memoria también puede ser un elemento que toda persona añade a su formación reflexiva política, filosófica o moral, ámbitos tutelados por la libertad de consciencia (art. $19 \mathrm{n}^{\circ}$ 6).

Un derecho muy relacionado con la memoria es la libertad de expresión, que faculta al titular para opinar e informar respecto de los acontecimientos del pasado sin censura previa, en cualquier forma y por cualquier medio (art. $19 \mathrm{~N}^{\circ} 12$ ). La memoria puede ser manifestada de múltiples maneras y la expresión artística suele ser empleada para metaforizar el recuerdo, actividad comprendida bajo la tutela de la libertad de creación

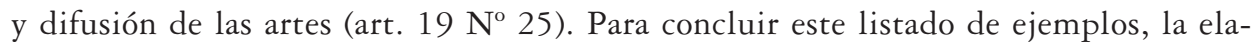
boración y conservación de la memoria requiere el acceso a los archivos e información pública (art. 8 inc. $2^{\circ}$ ).

Por tanto, realizándose una interpretación evolutiva y pro homine, debe concluirse que diferentes aspectos de la memoria están tutelados por varios derechos fundamentales consagrados constitucionalmente. Incluso, esta manera de interpretar la protección de la memoria puede conectarse con los derechos humanos garantizados por fuentes del Derecho internacional que se incorporan al ordenamiento interno mediante el art. 5 inc. segundo de la Constitución.

Como hemos señalado, la memoria tiene una relación profunda con el derecho a la reparación. Este último puede conceptuarse como el deber general de los Estados de devolver a la víctima a la situación inmediatamente anterior a la violación de derechos humanos sufrida, y en el evento de que eso fuere imposible, de reparar los efectos negativos de dicho acto ilícito ${ }^{7}$. Por tanto, la memoria es solo uno de los ámbitos abarcados por el derecho y deber de reparación. Este derecho tiene fuentes tanto convencionales, como el precitado art. 63 CADH o el art. 14 la Convención contra la tortura de Naciones Unidas, así como también fuentes consuetudinarias, como reconoce el fallo haciendo referencia a la jurisprudencia de la Corte IDH (consid. octavo).

Como indica la sentencia, para lograr estos fines no solamente se requieren compensaciones en dinero, sino también "medidas que se orienten a una educación integral en la materia -que no la mera instrucción o simple entrega de contenidos- a aquellas que propician la formación de una verdadera cultura en derechos humanos" (consid. octavo). Bajo esta forma de concebir la educación en derechos humanos, como formación integral, la Corte no accedió a la petición conjunta de colocar en lugar de las placas

\footnotetext{
${ }^{7}$ Corte IDH, 21.07.1989, Serie C No 7, párr. 26.
} 
conmemorativas un extracto de la sentencia, argumentando que "su sociabilización [de los derechos humanos] puede integrarse a la labor educativa que la institución tiene que llevar a cabo" (consid. duodécimo). Si bien era indispensable que se retiraran las placas e imágenes para la protección de los derechos afectados, cumplir el deber de reparación y tutelar la memoria, la persecución de estos mismos fines podría haber servido como sustrato argumentativo para acoger la referida petición conjunta.

Las medidas simbólicas de reparación ordenadas por la Corte de Apelaciones corresponden a las llamadas medidas de satisfacción, que apuntan al reconocimiento público de los hechos y la dignidad de las víctimas, expresando la solidaridad de la comunidad hacia ellas ${ }^{8}$. Por su parte, estas medidas también se vinculan con las garantías de no repetición, invocadas también por el recurrente, las que tienen la finalidad de evitar que violaciones de derechos humanos vuelvan a ocurrir. Esto se logra mediante una cultura donde exista consciencia pública acerca del desvalor intrínseco de las violaciones de derechos humanos. En ese contexto, la forma en que se recuerda a Contreras, retirando sus cuadros y no como si fuera un oficial más, muestra a la memoria en su faz de garantía de no repetición? ${ }^{9}$. Así, la Corte rechaza lo dicho por el recurrido en orden a que sus fotografías y placas forman parte de un registro histórico, porque para dichos fines bastan anotaciones en libros, fichas, documentos de destinaciones, entre otros (consid. noveno).

Por otra parte, se plantea la cuestión de la titularidad del derecho a la memoria. Aunque no fue discutido de esta manera, sí es posible tratar el tema a partir del hecho que el recurrido cuestionó la existencia de un daño concreto para el recurrente. En este sentido, la titularidad del derecho a la memoria es compleja, pues tiene una doble dimensión, individual y colectiva. La primera corresponde a testigos, partícipes o víctimas de los hechos, mientras que la memoria colectiva está conformada por relatos comunes construidos por una sociedad. En nuestro caso, la existencia de informes de comisiones de verdad, así como la investigación, el juzgamiento y sanción de crímenes de lesa humanidad, han contribuido a la formación de esta memoria social. Desde esta perspectiva, puede decirse que aun cuando las víctimas son indiscutiblemente titulares, la sociedad en su conjunto también tiene este derecho y podría ejercerlo cualquier persona. En este sentido, creemos que una acción de protección de esta naturaleza debiera haberse acogido aun cuando el recurrente no fuese víctima directa de la dictadura, o familiar de víctima, sino cualquier integrante de la sociedad. Esto, en alguna medida se ve ratificado por el hecho que, con ocasión de la noticia de la apelación del Ejército de Chile contra el fallo adverso, diversos actores de la sociedad civil se hicieron parte ante la Corte Suprema.

En relación con el debate pertinente a los sujetos obligados, es indudable que el Estado debe cumplir con las obligaciones de respeto, garantía y promoción de la memoria. Por esta razón, debe abstenerse de vulnerar el derecho a la memoria, siéndole prohibido obstaculizar las actividades destinadas a su (re)elaboración y difusión. La sentencia comentada adopta un razonamiento adecuado cuando señala que el Estado

\footnotetext{
${ }^{8}$ En este sentido, Correa, 2019, pp. 1058-1059; NASH, 2014, p. 81.

${ }^{9}$ Sferrazza y Bustos, 2019, p. 23.
} 
tiene la responsabilidad de reparar las consecuencias de la vulneración de derechos interconectados con la memoria.

Aunque la explicación y conservación del pasado constituyen ámbitos indubitados de disputa política ${ }^{10}$, un Estado en cuya jurisdicción acontecieron graves violaciones a los derechos humanos en el pasado reciente debe implementar políticas públicas que reconozcan la dignidad de las víctimas ${ }^{11}$. En un contexto transicional, el deber de neutralidad estatal no resulta quebrantado siempre que todas las violaciones a los derechos humanos calificables como tales a base de los estándares normativos nacionales e internacionales, sean incluidas en el marco de tales políticas.

\section{BIBLIOGRAFÍA}

Blustein, Jeffrey, 2012: "Human Rights and the Internationalization of Memory", Journal of Social Philosophy, vol. 43(1), pp. 19-32.

Comisión de Derechos Humanos, 2005: "Promoción y protección de los derechos humanos. Impunidad. Informe de Diane Orentlicher, Experta independiente encargada de actualizar el Conjunto de principios para la lucha contra la impunidad", E/CN.4/2005/102, 18.02.2005. Disponible en https://documents-dds-ny.un.org/doc/UNDOC/GEN/G05/111/06/PDF/ G0511106.pdf?OpenElement. [Fecha de consulta: 27.04.2020].

Correa, Cristián, 2019: “Artículo 63”, en Christian Steiner et al. (editores), Convención Americana sobre Derechos Humanos. Comentario, $2^{\mathrm{a}}$ ed., Konrad Adenauer Stiftung, pp. 1019-1099.

DulitzKy, Ariel, 2017: "La memoria en la jurisprudencia de la Corte Interamericana de Derechos Humanos”, en Oscar Parra Vera et al. (editores), La lucha por los derechos humanos hoy. Estudios en homenaje a Cecilia Medina Quiroga, Valencia, Tirant lo Blanch, pp. 581-604.

Escudero Alday, Rafael, 2013: “Jaque a la Transición: análisis del proceso de recuperación de la memoria histórica”, Anuario de Filosofía del Derecho, No 29, pp. 319-340.

LUTHER, Jörg, 2010: "El derecho a la memoria como derecho cultural del hombre en democracia", Revista Española de Derecho Constitucional, No 89, pp. 45-76.

Nash, Claudio, 2014: Responsabilidad internacional del Estado, Santiago, Legal Publishing.

Pugiotto, Andrea, 2009: "Quando (e perché) la memoria si fa legge", Quaderni costituzionali, $\mathrm{N}^{\circ}$ 1, pp. 7-35.

Sferrazza, Pietro y Bustos, Francisco, 2019: "Violaciones a los Derechos Humanos y derecho a la memoria en Chile”, en Hugo Castro (coodinador), Memoria, patrimonio y ciudadanías, Valparaíso, Universidad de Playa Ancha, pp. 15-56.

\section{Jurisprudencia Citada}

Corte IDH. Velásquez Rodrígez vs. Honduras. Sentencia de 21 de julio de 1989. Serie C No 7.

Corte IDH. Cantoral Benavides vs. Perú. Reparaciones. Sentencia de 3 de diciembre de 2001. Serie $\mathrm{C} \mathrm{N}^{\circ} 88$.

Corte IDH. Bámaca Velásquez vs. Guatemala. Sentencia de 22 de febrero de 2002. Serie C No 91.

\footnotetext{
${ }^{10}$ Pugiotto, 2009, p. 21; Escudero Alday, 2013, pp. 331-332

${ }^{11}$ Blustein, 2012, pp. 22-23, añadiendo que se trata de un deber integeneracional.
} 
Corte IDH. Trujillo Oroza vs. Bolivia. Reparaciones y costas. Sentencia de 27 de febrero de 2002. Serie $C \mathrm{~N}^{\circ} 92$.

Corte IDH. Bulacio vs. Argentina. Fondo, Reparaciones y Costas. Sentencia de 18 de septiembre de 2003. Serie C No 100.

Corte IDH. Myrna Mack Chang vs. Guatemala. Sentencia de 25 de noviembre de 2003. Serie C N 101. 